\title{
Shallow to intermediate resistivity features of the Colfiorito Fault System inferred by DC and MT survey
}

\author{
Ida Diaferia, Mariano Loddo, Domenico Schiavone and Agata Siniscalchi \\ Dipartimento di Geologia e di Geofisica, Università degli Studi di Bari, Italy
}

\begin{abstract}
Over the last decade electromagnetic (EM) measurements have provided new constraints on the upper-crustal structure of the major fault zones in the world, both when they act as conduit and as a barrier, due to strong sensitivity of resistivity to fluids circulation and mineralization. On the track of a high impact magnetotelluric (MT) study performed across the San Andreas Fault, high resolution EM data were collected in the Colfiorito epicentral area along profiles crossing some main fault lineaments. Being the study focussed both on shallow that on intermediate resistivity distribution in the brittle upper-crust, a MT profile was integrated by several electrical resistivity tomographies (ERT). The latter were successful in locating faults even where the structures are buried by a wide covering of Quaternary deposits and in the recognition of different electrical signatures of the faults. MT resistivity model crossing Mt. Prefoglio normal fault clearly imaged the typical thrust structures of the area and a high conductive zone spatially related to the fault. Seismicity seems to be located outside such conductive area, whose behaviour suggests a fluidised and altered zone incapable of supporting significant stress internally.
\end{abstract}

Key words Colfiorito fault system - magnetotellurics - geoelectrics - fluids

\section{Introduction}

The presence of an electrically conducting fluid, such as saline pore water, strongly influences the overall resistivity of the crustal rocks, thus favouring the application of prospecting methods based on electrical and electromagnetic physical properties, in detailed imaging of fault zones.

In particular, the MT method uses the fluctuation of natural electromagnetic (EM) fields to

Mailing address: Dr. Agata Siniscalchi, Dipartimento di Geologia e di Geofisica, Università degli Studi di Bari, Campus Universitario, Palazzo di Scienze della Terra, Via E. Orabona 4, 70125 Bari, Italy; e-mail: sinia@geo.uniba.it map the spatial distribution of the Earth's electrical resistivity. For the basic theoretical concepts and the practical field indications of the method the reader can refer to a recent book by Simpson and Bahr (2005).

In traditional MT survey usually large separations (about some kilometres) between MT soundings were adopted to detect fault area anomalies, thus mis-estimating both the true extent of the fault area and the correct resistivity contrast with the host rocks. On the contrary, more closely spaced data yield high-resolution images of electrical conductivity variations within and near the fault zone up to several $\mathrm{km}$ of depth (Eberhart-Phillips et al., 1995; Unsworth et al., 1999; Ingham, 2005).

In the last decade, the introduction of a new MT measurement array, the continuous array profiling (Unsworth et al., 1999), firstly applied for a high resolution MT study across two segments of the San Andreas Fault, demonstrated the feasibility of MT to give significant contribu- 
tions in fault zones characterization (Unsworth et al., 1997).

Since imaging at depth is strictly related to frequency, a gap of information exists on the shallow resistivity distribution, caused by the typical frequency range of the MT method. In addition, there is an inherent trade-off between shallow structures and the deeper response of the fault zone. Shallow structures must be accurately determined if deeper ones are to be reliably imaged. Thus, in order to control the shallow part of the subsurface, magnetotelluric measurements can be integrated with DC survey. This approach both constrains the MT model in the first hundred metres of depth and estimates eventual static shift effects in the high frequency MT data. Moreover, when the DC method is carried out in the tomographic configuration (earth resistivity tomography, ERT), proves effective for supporting studies in tectonically active areas (Diaferia et al., 2006).

On the basis of the previous discussion, a combined use of ERT and magnetotelluric profiling was applied in the Colfiorito epicentral area of the earthquake sequence, which struck the Umbria-Marche region during 1997-1998.

The MT profile was generally performed with a $100 \mathrm{~m}$ station spacing, and the MT transfer function was estimated in the $0.01 \mathrm{~Hz}$ to 250 $\mathrm{Hz}$ frequency range. Even though it was not possible to keep this spatial resolution all over the profile, the high density gained in the hanging wall of the fault was sufficient to image the electrical conductivity variations in the fault zone, although with a reduced resolution, as tested also on synthetic models. Moreover, along the same line, in the area of the main known geological discontinuities, the MT profile was integrated with a $1 \mathrm{~km}$ long dipole-dipole electrical resistivity tomography.

This paper presents and discusses the results obtained from the combined application of the two methodologies.

\section{Geological setting}

The Colfiorito area is located in the inner part of the Umbria-Marche Apennines, an eastward verging fold and thrust belt, representing the eastern portion of the Northern Apennines of Italy. Figure 1 shows the location of all the electric profiles surveyed in the area and the magnetotelluric stations together with a structural sketch of the Colfiorito area.

The study area is characterized by compressional structures (Upper Miocene in age), displaced by a system of later normal faults, generated during the subsequent (Late Pliocene to present) extensional phase. These faults are still active, and responsible for the moderate to high $(5<\mathrm{M}<7)$ seismicity of the region (Chiaraluce et al., 2005). The major normal faults, pertaining to the Colfiorito Fault System (CoFS; heavy black in fig. 1), consist of a set of SW-dipping normal faults, roughly aligned in the $\mathrm{N} 150^{\circ} \mathrm{E}$ direction, showing a dip in the range $50^{\circ}-80^{\circ}$ (Diaferia et al., 2006). Moreover, the extensional tectonics yielded a set of Pleistocene intramountain basins, located in the down-thrown hanging-wall block

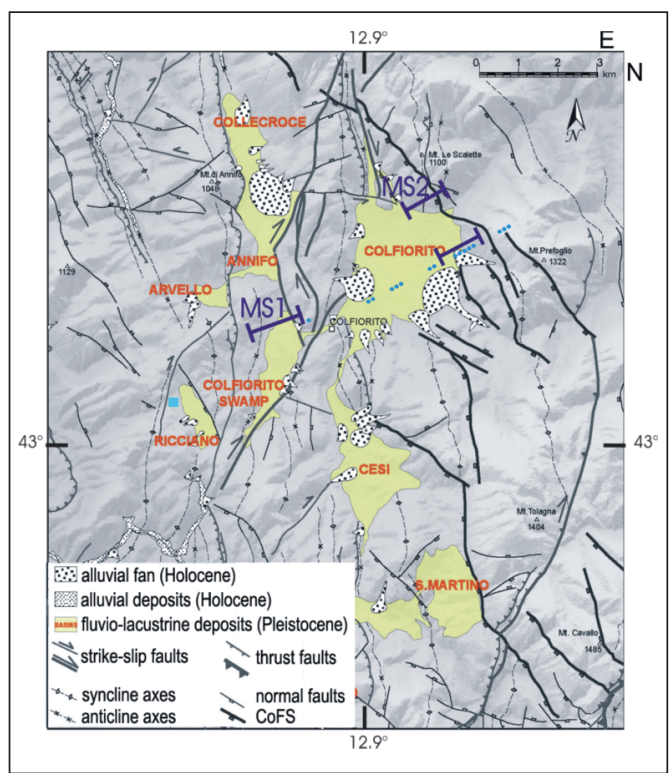

Fig. 1. Geologic-structural sketch map of the Colfiorito area and location of the geophysical measurements (modified after Diaferia et al., 2006). ERT profiles (MS) are drawn in blue and MT station sites in cyan. The filled square indicates the location of the nearest MT remote reference station. 
of the CoFS (fig. 1). Our study area is mainly located in the Colfiorito Basin, filled with LowerMiddle Pleistocene fluvio-lacustrine deposits, which reach a maximum thickness of about 120 $\mathrm{m}$. Along the MT transect the basin becomes thinner (Di Giulio et al., 2003).

Extended discussions on geological and seismological data of the area are present in other papers in this volume.

\section{Data acquisition and processing}

An MT transect consisting of 17 remote referenced MT soundings was surveyed on the centre of the Colfiorito Basin. The line is about $6 \mathrm{~km}$ long, with a NE-SW direction, approximately normal to the average trend of the Prefoglio fault segment (fig. 1). Part of the MT data were acquired according to the «magnetotelluric array profiling technique». In this scheme, the electric fields are sampled on the surface with a continuous series of dipoles laid end-to-end. The acquisition system consisted of two 24 bit A/D homemade electromagnetic devices, which, located at two different sites, records the time series data synchronously thanks to a GPS positioning system. According to Gamble et al. (1979), the remote reference technique allows the removal of coherent noise. In our study we used different remote reference stations at increasing distance from the investigated area. Figure 1 shows the nearest one, located at $8 \mathrm{~km}$ from Prefoglio.

The system is able to record up to 14 data channels. The horizontal magnetic fields were measured, at the centre of each array, with BF4 EMI induction coils, while the electric fields are generally acquired by five dipoles along the profile and three dipoles in a perpendicular direction, with $100 \mathrm{~m}$ dipole length. In particular, due to the rough topography, man-made buildings and presence of cultivation, in many sites of the investigated area short magnetotelluric continuous profiles, 200-300 m long, were performed. It was only close to the Prefoglio fault that a $500 \mathrm{~m}$ long MT profile was possible.

After a visual inspection, data segments that did not present a high noise level or a large number of outliers were selected and processed for estimating the MT transfer functions in the 0.01-

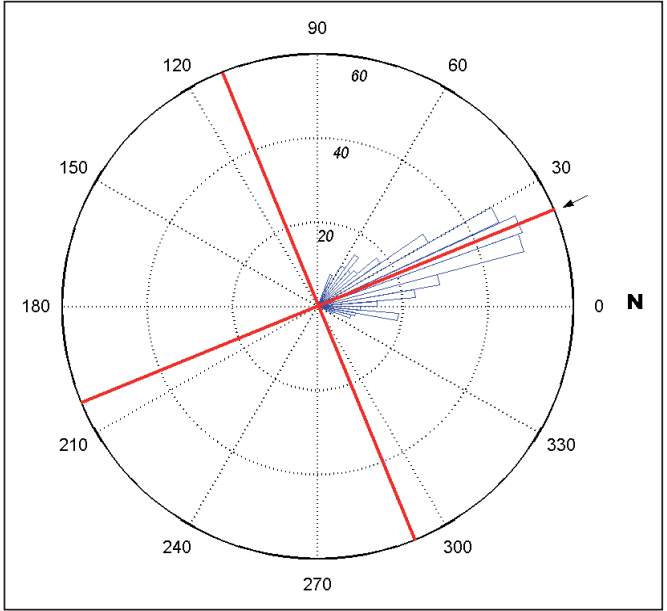

Fig. 2. Rose histograms of geoelectric strike for periods up to $10 \mathrm{~s}$ and all soundings as calculated via tensor decomposition (Weaver et al., 2000). Italic numbers and the arrow indicate respectively the number of samples in each interval and the best fit geoelectric strike direction. Solid lines indicate an average local geological strike and the orthogonal direction which coincides with the choosen profile direction.

$250 \mathrm{~Hz}$ frequency range. Then, the apparent resistivities and phases were computed using three different statistical procedures: the robust single station (SS), the robust remote reference (RR) and the robust multivariate error in variable (RMEV) (Egbert, 1997) estimation methods. Significant differences among the three methods in the highest frequency range $(5-250 \mathrm{~Hz})$ were observed, with the presence of near-field effects in the SS estimate.

Moreover, the RMEV method demonstrated its efficiency in strongly reducing the bias with respect to the SS and RR methods and was selected for the data processing. In order to further enhance the signal-to-noise ratio for all time series we have implemented the Egbert code with a filter for the removal of the contamination by the $50 \mathrm{~Hz}$ power line and its harmonics. By applying the decomposition scheme by Weaver et al. (2000) we estimated the possibility of a 2D approach. A mean strike angle of about $\mathrm{N} 23^{\circ} \mathrm{W}$ was recovered for periods up to $10 \mathrm{~s}$ and for all soundings (fig. 2). This result is consistent with 
the structural surface data, allowing also assigning the correct direction of the TM and TE polarization modes.

As previously discussed, the MT survey was complemented by three electrical resistivity tomographies (ERT), adopting a multiscale approach (Diaferia et al., 2006). Two of the three tomographic surveys (MS1 and MS2) (see fig. 1) were already discussed in the cited paper. In this study we present the MS3 profile carried out along the MT transect, discussing its main features together with the parallel MS2 line.

Multicore cables and an automatic acquisition system (Syscal R2) were adopted for ERT measurements and the dipole-dipole array was chosen for its better horizontal resolution. Three different electrode spacings, ranging from $5 \mathrm{~m}$ to $60 \mathrm{~m}$, were used.

The quantitative inversion of the experimental data was performed using the RES2DINV software (Geotomo Software, 2002).

\section{MT and ERT modelling}

Due to the severe topography it was not possible to carry out both DC and MT measurements in the immediate vicinity of the Prefoglio fault. However, the MS3 profile and the continuous MT survey were located on the hangingwall of the fault where large changes in resistivity and static shift effects associated with the basin were expected.

Before data inversion the potential to recover a conductive fault zone at depth adopting the actual MT sounding location was investigated through a numerical modelling.

In the simulation we used a model representing a simplified geological and structural sketch along the profile. A $10 \%$ random noise was added to the apparent resistivity and a $4 \%$ to the apparent phase before inversion.

Figure 3 shows the synthetic model and the resistivity section recovered from the inversion. The section indicates that information can be determined on the existence and main features of the fault with the adopted sounding spacing.

Since a wide covering of Quaternary deposits buried the structures and geological formations in the surveyed area, detailed geologi-

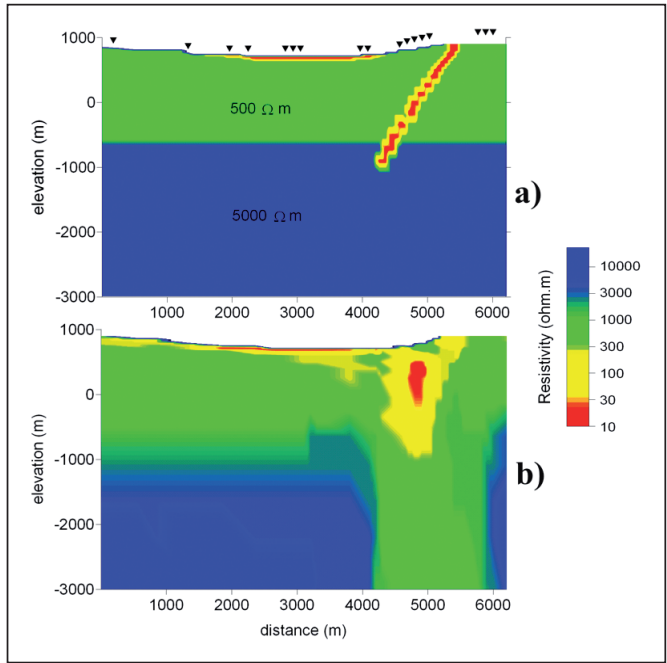

Fig. 3a,b. a) Synthetic model used for the numerical test. A $150 \mathrm{~m}$ wide, $10 \mathrm{ohm} \mathrm{m}$ dipping fault zone is modelled. b) Resistivity model resulting from the inversion of model response data.

cal surface data is lacking. Therefore, the geological interpretation of the resistivity model was performed by comparing it with the results of the MS2 line, on the basis also of the lithological classification of the resistivity shown in Table I (Diaferia et al., 2006).

The result of the interpretation of the MS3 electrical survey (fig. 4a) disclose a prevailing stratified behaviour in the hanging-wall of the COFS. Such layering coincides, both in resistivity values and thicknesses, with the northeastern part of a previously published MS2 model (fig. $4 \mathrm{~b}$ ) carried out along a parallel profile, $2 \mathrm{~km}$ apart toward NW. In the latter model other discontinuities are disclosed in the southeastern side associable with minor faults (see fig. 4c).

The analysis of the MS3 model shows the presence of a near-surface lateral resistivity change located beneath the MR survey. In this zone a correction of the static shift effects was performed.

Given that the near surface electrical structures are better defined by the ERT data than by the MT data the full ERT model was used as a soft constraint during MT modelling. 


\section{MT resistivity model}

The MT data were inverted using the regularized algorithm of Rodi and Mackie (2001) considering the topography.

The model shown in fig. 5 results from a two step inversion process:

- An initial model was selected, made by a $300 \Omega \mathrm{m}$ homogeneous half space with the recovered ERT model in the eastern portion, and, in the central part, the Colfiorito basin characterized by a constant $15 \Omega \mathrm{m}$ resistivity and a depth of $100 \mathrm{~m}$. This model was used for the inversion using only the TM data in order to identify first order features. A regularization parameter $\tau$ equal to 30 was used.

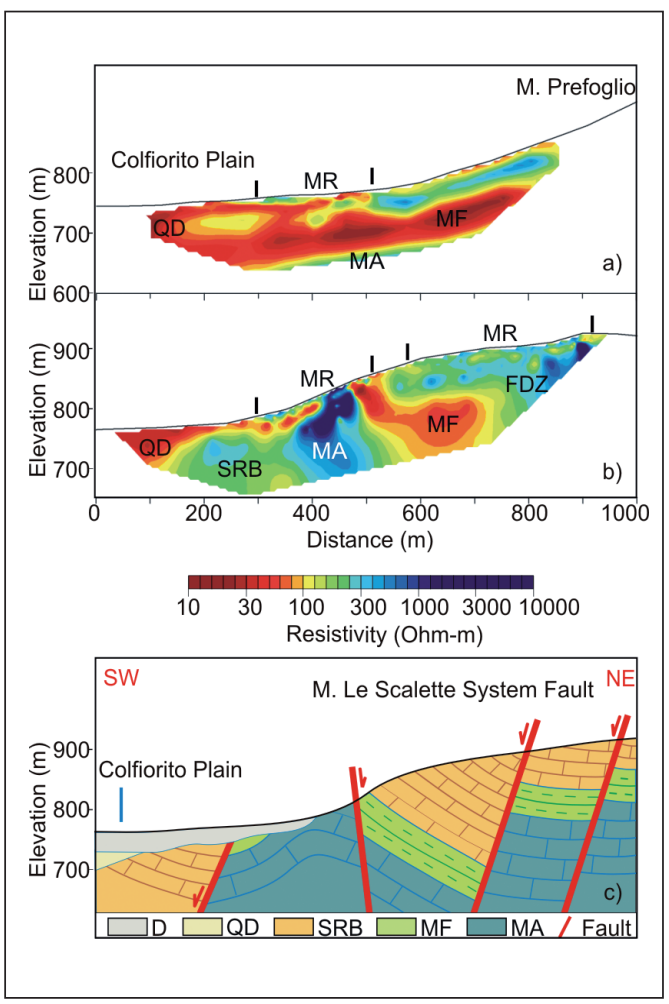

Fig. 4a,b. MS3 (a) and MS2 (b) resistivity models and geological section along MS2 line (c). QD: Quaternary deposits; SRB: Scaglia Rossa/Bianca Fm.; MF: Marne a Fucoidi Fm; MA: Maiolica Fm.

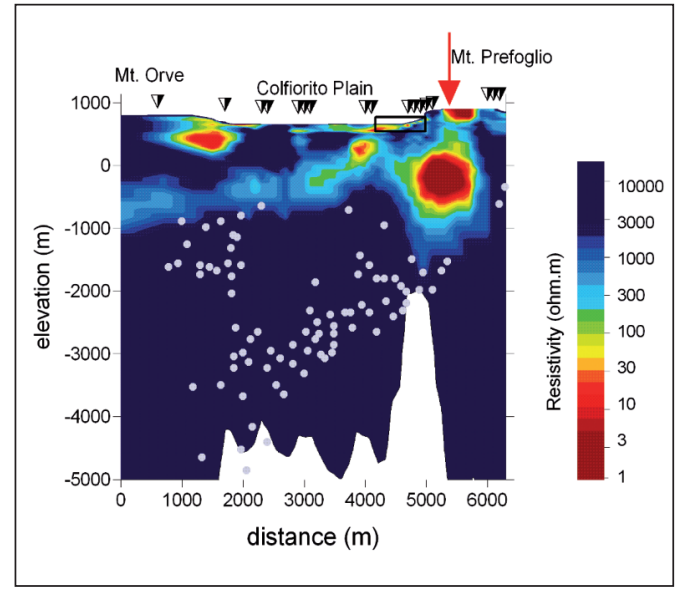

Fig. 5. MT resistivity model obtained by joint inversion of TE and TM modes; normalized rms=3.7. Aftershocks (gray circles) are redrawn after Chiaraluce et al. (2005). The red arrow marks the fault position. The black rectangle contour the MS3 section.

- Afterwards, the broad features recovered by the previous processing step were incorporated into starting models for the final (TM + $\mathrm{TE}$ ) inversions, without fixing them during the processing. For this step a regularization parameter $\tau$ equal to 5 was chosen.

The regularization factors were chosen by the analysis of the trade-off curve between data misfit and model smoothness, determined through a series of trial inversions. A normalized r.m.s. misfit value of 3.7 ( 3 for TM mode only) was obtained assuming error floors of $20 \%$ in apparent resistivity and 5\% in phase.

In the figure the ERT model size was outlined. Besides, a comparable color scale for the ERT and MT models was used. Because the ERT model does not change substantially during the inversion process, it means that, in this context, the ERT and MT investigation depths are to be considered complementary, without significant overlapping.

The comparison between experimental and model responses is shown in fig. 6. Following Schwalenberg et al. (2002), normalized average sensitivities were calculated from the sen- 


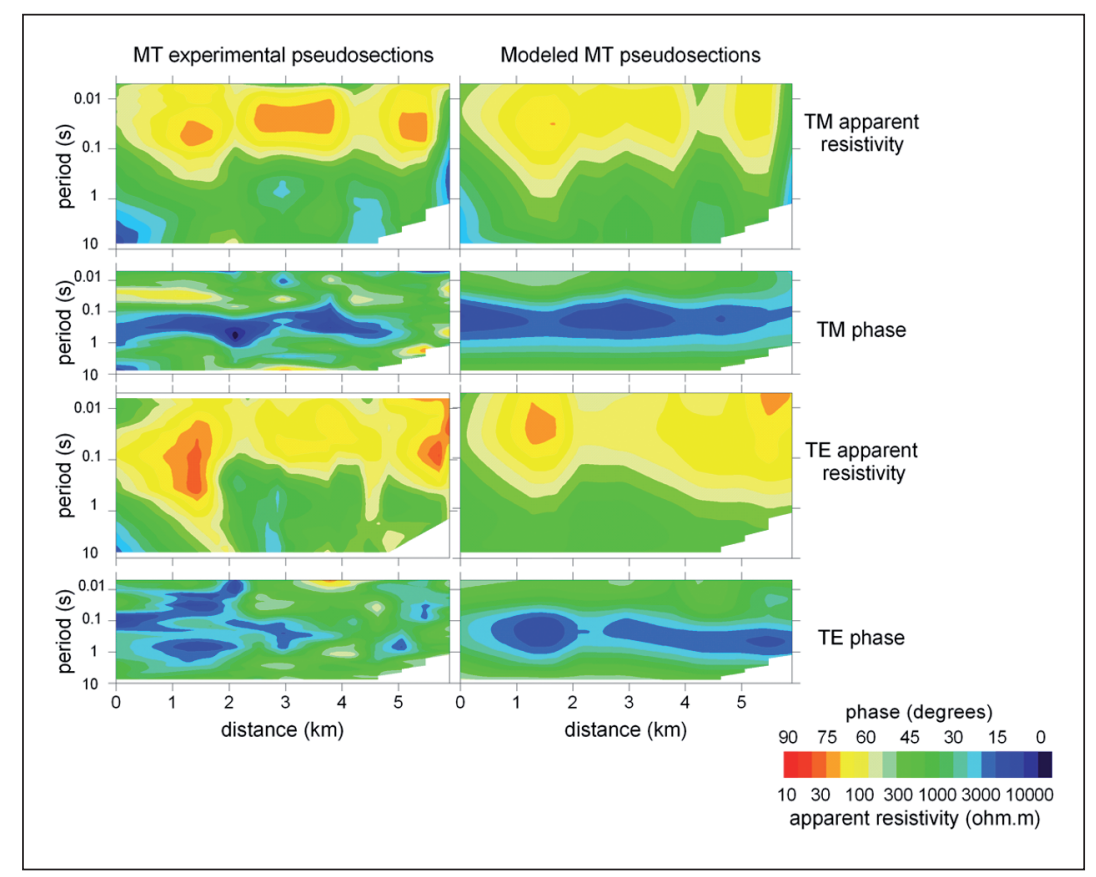

Fig. 6. TE and TM mode MT apparent resistivity and phase pseudosections of the experimental data (on the left) and the synthetic data generated by the model in fig. 5 (on the right).

sitivity matrix; the resulting values were used to fade out deeper, unresolved, model structures from the interpretation. The $10^{-4}$ isoline was finally selected as limiting value for the resolved model.

A general agreement exists between experimental and modeled pseudosections.

\section{Discussion and concluding remarks}

The resistivity model, best fitting the data up to a period of $10 \mathrm{~s}$, images, in its shallow part, alternating resistive and conductive zone well representing the typical thrust structure of the area described by Miller et al. (2004), supported also by reflection seismic results (Stucchi et al., 2006). Resistive and conductive signatures of this structure can be respectively associated (see table I) to compact Maiolica Formation and the presence, within the thrust, of Marne a Fucoidi (Mirabella and Pucci, 2002).

Across the fault, an important large conductive area is pointed out, almost vertically extending downward to the first $\mathrm{km}$ of depth. The presence of such an anomalous zone is not evidenced in the results of other geophysical surveys carried out in the area. The conductive signature of the fault can also be explained by the presence of fluids in fracture nets. Thus, a continuity exists between the shallow image of the fault area analyzed by Diaferia et al. (2006) and the intermediate one that represents the main contribution of this paper.

If a fluid is considered to explain the across the fault conductive structure, the very low resistivity values of this structure must be ascribed to the high fluid salinity. According to Cello et al. (2001), high salinity fluids are always present in samples collected from the faults bordering the main basins, whereas they 


\begin{tabular}{|l|c|}
\hline GEOLOGICAL FORMATION & Resistivity (Ohm-m) \\
\hline Scaglia Cinerea/Nariegata (SCV) & $7-10$ \\
\hline ScagliaRossa/Bianca (SRB) & $60-200$ \\
\hline Marne a Fucoidi (MF) & $10-30$ \\
\hline Maiolica (MA) & $300-3000$ \\
\hline
\end{tabular}

Table I. Mean resistivity ranges of the geological formations deduced by well logs (after Diaferia et al., 2006).

have never been observed in samples collected across subsidiary structures.

This interpretation is also supported by the correlation of the MT section with seismological results. In fact, the aftershock locations (Chiaraluce et al., 2005) show a gap in correspondence with the conductive characteristics of the rocks (see fig. 5). Again, the presence of fluids could explain such a behaviour. In fact, according to models of the earthquake cycle by Sleep and Blanpied (1992) and Byerlee (1993), fluids are believed to enter the highly permeable and porous fault zone following an earthquake. Over time, shearing, creep compaction, and mineralization form low-permeability seals which isolate the fault zone from the surrounding country rock. It is at asperities of this border zone that seismic events are potentially spawned (Wannamaker et al., 2004). Fluid filled and altered zones are incapable of supporting significant stress internally, representing a barrier to the migration of earthquakes toward the surface. Thus, the recovered model supports the hypothesis of a listric depth geometry of the fault also suggested in Stucchi et al. (2006).

We applied combined geophysical methods to characterize some main features of the Colfiorito fault system from surface to until some kilometres of depth.

The joint interpretation of a DC multiscale tomography and MT measurements in continuous profiling arrangement proved to be effective in imaging some peculiar features of the fault zones. In particular, the electrical characteristics of the recovered section well explain the seismological features of the studied area.

\section{Acknowledgments}

This research was supported by GNDT and MIUR grants.

\section{REFERENCES}

BYerLeE, J. (1993): Model for episodic flow of high-pressure water in fault zones before earthquakes, Geology, 21, 303-306.

Cello, G., C. Invernizzi, S. Mazzoli and E. Tondi (2001): Fault properties and fluid flow patterns from Quaternary faults in the Apennines, Italy, Tectonophysics, 336, 63-78.

Chiaraluce, L., M.R. Barchi, C. Collettini, F. MirabelLA, and S. PUCCI (2005): Connecting seismically active normal faults with Quaternary geological structures in a complex extensional environment: The Colfiorito 1997 case history (northern Apennines, Italy), Tectonics, 24, TC1002, doi:10.1029/2004TC001627.

Diaferia, I., M.R. Barchi, M. Loddo, D. Schiavone and A. SinISCALCHI (2006): Detailed imaging of tectonic structures by multiscale Earth resistivity tomographies: The Colfiorito normal faults (central Italy), Geophys. Res. Lett., 33, L09305, doi:10.1029/2006GL025828.

Di Giulio, G., A. Rovelli, F. Cara, R.M. Azzara, F. MARrA, R. BASILI and A. CASERTA (2003): Long-duration asynchronous ground motions in the Colfiorito plain, central Italy, observed on a two-dimensional dense array, J. Geophys. Res., 108 (B10), 2486, doi:10.1029/2002JB002367.

Eberhart-Phillips, D., W.D. Stanley, D.B. Rodriguez, and W.J. LUTTER (1995): Surface seismic and electrical methods to detect fluids related to faulting, J. Geophys. Res., 100 (B7), 12919-12936, doi: 10.1029/94JB03256.

EGBERT, G.D. (1997): Robust multiple-station magnetotelluric data analysis, Geophys. J. Int., 130, 475-496.

Gamble, T.D., W.M. Goubau and J. Clarke (1979): Magnetotellurics with a remote magnetic reference, Geophysics, 44, 53-68.

Geotomo SoFtwARE (2002): RES2DINV-Geoelectrical imaging $2 \mathrm{D} \& 3 \mathrm{D}$, user manual version 3.5 (www.geoelectrical.com).

INGHAM, M. (2005): High resolution electrical imaging of fault zones, Phys. Earth Plan. Int., 150, 93-105.

Miller, S. A., C. Collettini, L. Chiaraluce, M. Cocco, M.R. BARCHI and B.J.P. KAUS (2004): Aftershocks driven by a high pressure $\mathrm{CO} 2$ source at depth, Nature, 427, 724-727, doi:10.1038/nature02251.

Mirabella, F. and S. PUCCI (2002): Integration of geological and geophysical data along a section crossing the region of the 1997-1998 Umbria-Marche earthquakes (Italy), Boll. Soc. Geol. It., volume speciale n.1, 891-900.

RodI, W. and R.L. MACKIE (2001): Nonlinear conjugate gradients algorithm for 2-D magnetotelluric inversion, Geophysics, 66, 174-187.

SCHWALENBERG, K., V. RATH and V. HAAK (2002): Sensitivity studies applied to a two-dimensional resistivity model from the Central Andes, Geophys. J. Int., 150, 673-686. 
SimpSON, F. and H. BAHR (2005): Practical magnetotellurics. Cambridge University Press, Cambridge UK. ISBN 0521817277.

SLEEP, N.H. and M.L. BlanPIED (1992): Creep, compaction and the weak rheology of major faults, Nature, 359, 687-692.

Stucchi, E., F. Mirabella and M.G. Ciaccio (2006): Comparison between reprocessed seismic profiles: Seismologic and geologic data. A case study of the Colforito earthquake area, Geophysics, 71 (2), B29-B40, doi: 10.1190/1.2187709.

Unsworth, M., G. EgBerT and J. BoOKer (1999): High-resolution electromagnetic imaging of the San Andreas fault in
Central California, J. Geophys. Res., 104 (B1), 1131-1150. Unsworth, M.J., P.E. MAlin, G.D. Egbert and J.R. BooKER (1997): Internal structure of the San Andreas fault at Parkfield, California, Geology, 25 (4), 359-362.

Wannamaker, P.E., T.G. Caldwell, W.M. Doerner and G.R. JIRACEK (2004): Fault zone fluids and seismicity in compressional and extensional environments inferred from electrical conductivity: the New Zealand Southern Alps and U. S. Great Basin, Earth Planets Space, 56, 1171-1176.

Weaver, J.T., A.K. Agarwal and F.E.M. Lilley (2000): Characterization of the magnetotelluric tensor in terms of its invariants, Geophys. J. Int., 141, 321-336. 